\title{
CHI PHÍ ĐIỀU TRI NộI TRÚ VIÊM PHỔI CỦA BỆNH NHÂN Có THẺ BẢO HIỂM Y TẾ TẠI HÀ NộI NĂM 2018
}

\author{
Nguyễn Quỳnh Anh*, Nguyễn Đức Hòa**, Nguyễn Thành Đạt***
}

\section{TÓM TẮT}

Mục tiêu: Xác định chi phí điều trị nội trú viêm phổi của 44.678 hồ sơ thanh toán bảo hiểm y tế (BHYT) của bệnh nhân có thẻ BHYT tại Hà Nội năm 2018. Phương pháp nghiên cứu: Nghiên cứu mô tả cắt ngang, hồi cứu số liệu thứ cấp của 44.678 bản ghi chi phí khám chữa bênh (KCB) BHYT viêm phổi tại 71 cơ sở KCB trên địa bàn Hà Nội. Kết quả: Chi phí điêu trị nội trú trung bình của bệnh viêm phổi là 5.750 .463 đồng/lượt, trong đó cơ cấu chi phí trung bình một đợt điều trị bệnh viêm phổi thì chi phí giường bênh chiếm tỷ trọng lớn nhất $(32,4 \%)$, tiếp đến là tiền thuốc $(31,7 \%)$, xét nghiệm và chẩn đoán hình ảnh (XN và CĐHA) (20,08\%). Kết luận và khuyến nghị: Có sự chênh lệch về chi phí điều trị nôi trú bệnh viêm phổigiữa các đối tượng đi KCB trái tuyến và đúng tuyến, tần suất đi $K C B$ nội trú của đối tượng tham gia BHYT theo hộ gia đình chưa nhiều vì vậy cân khuyến nghi phát triển y tế cơ sở; quản lý việc $K C B$ vượt tuyển, trái tuyến; tuyên truyền để người dân chủ động tham gia BHYT theo đối tượng hộ gia đình.

Tư khóa: viêm phổi, chi phí, bảo hiểm y tế.

\section{SUMMARY}

\section{COST OF INPATIENT PNEUMONIA TREATMENT OF HEALTH INSURED PATIENTS IN HANOI IN 2018}

Objective: Determine the cost of inpatient treatment for pneumonia of 44,678 health insurance payment records of patients with health insurance cards in Hanoi in 2018. Methods: A cross-sectional descriptive study, retrospective secondary data of 44,678 records of medical examination and treatment costs covered by pneumonia insuranceat 71 medical facilities in Hanoi. Results: The average cost of inpatient treatment forpneumonia was 5,750,463 VND/time, in which the average cost structure for a courseof pneumonia treatment, the cost of hospital beds accounts for the largest proportion (32.4\%), followed by pre-medication $(31.7 \%)$, laboratory tests and imaging studies (X-ray and CPR) (20.08\%); Conclusions and recommendations: There is a difference in the cost of inpatient treatment for pneumonia between the subjects who go for medical care at the wrong line and at the right level, the frequency of inpatient medical care of the participants with health insurance according to the household is

*Trường Đai học Y tế công cộng

** Bảo hiếm xã hôi Hà Nội

***Bảo hiểm xã hôi Việt Nam

Chịu trách nhiệm chính: Nguyễn Quỳnh Anh

Email: nqa@huph.edu.vn

Ngày nhận bài: 9.7.2021

Ngày phản biên khoa hoc: 3.9.2021

Ngày duyệt bài: 10.9 .2021 not much. therefore, it is necessary to recommend the development of grassroots health; managing the medical services crossing the line, the wrong line; propagandize for people to actively participate in health insurance according to household objects

Keywords: pneumonia, cost, health insurance

\section{I. ĐẶT VẤN ĐỀ}

Viêm phổi là bệnh phổ biến và thường gặp tại trẻ nhỏ, chi phí y tế cho bệnh viêm phổi là một gánh nặng cho xã hội, đặc biệt ở nước đang phát triển như Việt Nam. Hiện nay, với việc có đến trên $90 \%$ dân số tham gia BHYT(1), trong đó $100 \%$ trẻ em dưới 6 tuổi đều có thẻ BHYT, đồng thời danh mục thuốc, dịch vụ kỹ thuật, vật tư y tế thuộc phạm vi thanh toán của quỹ BHYT đã đáp ứng được việc điều trị bệnh viêm phổi. Để tìm hiểu về chi phí điêuu trị nôi trú của người có thẻ BHYT tai các bênh viện trên đia bàn thành phố Hà Nội năm 2018, chúngtôi đã tiến hành nghiên cứu đề tài "Chi phí điều trị nội trú viêm phổi của người có thẻ BHYT tại Hà Nội năm 2018" với mục tiêu xác định chi phí điêu trị nội trú của bệnh viêm phổi dưới góc độ người quản lý quỹ BHYTT.

II. ĐỐI TƯỢNG VÀ PHƯƠNG PHÁP NGHIÊN CỨU Thiết kế nghiên cứu: mô tả cắt ngang.

Thời gian, địa điểm nghiên cứu: Nghiên cứu được thực hiện tại Bảo hiểm xã hội Việt Nam từ tháng 04 đến tháng 06 năm 2020.

Đối tượng nghiên cứu: Các bản ghi số liệu chi phí KCB nội trú Viêm phổicủa người có thẻ BHYT tại 71 cơ sở y tế trên địa bàn thành phố Hà Nội đề nghị thanh toán BHYT năm 2018.

\section{Cỡ mẫu và cách chọn mẫu}

Cõ mẫu: Toàn bộ 44.678 bản ghi chi phí KCB BHYT nội trú phát sinh tại cơ sở y tế trên địa bàn thành phố Hà Nôi năm 2018.

Cách chọn mẫu: Chọn toàn bộ 44.678 bản ghi chi phí KCB BHYT nội trú phát sinh tại cơ sở y tê trên địa bàn thành phố Hà Nội có mã bệnh chính trong hồ sơ bệnh án là J18, không có mã bệnh khác kèm theo.

Phương pháp phân tích số liệu: Số liêu được nhập vào phân mêm Navicat, phân tích bằng phần mềm SPSS 20.0.

Đạo đức nghiên cứu: Nghiên cứu được tiến hành với sự đông ý của Bảo hiểm xã hội Việt Nam và Bảo hiểm xã hội thành phố Hà Nội. Nghiên cứu được chấp thuận bởi Hội đồng đạo 
đức trong nghiên cứu y sinh học của Trường Đại học $Y$ tế công cộng theo Quyết định số 164/2020/YTCC-HD3 ngày 24/4/2020.

\section{KẾT QUẢ NGHIÊN CỨU}

Mô tả thông tin chung về đối tượng nghiên cứu

Bảng 1. Thông tin chung của đôi tượng nghiên cứu ( $n=44.678)$

\begin{tabular}{|c|c|c|c|}
\hline \multicolumn{2}{|c|}{ Các đă } & \multicolumn{2}{|c|}{ T'ân suấtTỷ lệ(\%) } \\
\hline \multirow{2}{*}{ Giới } & Nam & 26.614 & $59,57 \%$ \\
\hline & Nữ & 18.064 & $40,43 \%$ \\
\hline \multirow{3}{*}{$\begin{array}{c}\text { Nhóm } \\
\text { tuổi }\end{array}$} & $<45$ & 37.13 & $83,11 \%$ \\
\hline & $45-60$ & 1.814 & $4,06 \%$ \\
\hline & $>60$ & 5.734 & $12,83 \%$ \\
\hline \multirow{6}{*}{$\begin{array}{l}\text { Nhóm đối } \\
\text { tượng tham } \\
\text { gia BHYT }\end{array}$} & Nhóm 1 & 632 & $1,42 \%$ \\
\hline & Nhóm 2 & 2.553 & $5,71 \%$ \\
\hline & Nhóm 3 & 38.454 & $86,07 \%$ \\
\hline & Nhóm 4 & 1.248 & $2,79 \%$ \\
\hline & Nhóm 5 & 1.788 & $4,00 \%$ \\
\hline & Nhóm 6 & 3 & $0,01 \%$ \\
\hline \multirow{5}{*}{$\begin{array}{c}\text { Mã } \\
\text { quyền lợi }\end{array}$} & 1 & 34.989 & $78,31 \%$ \\
\hline & 2 & 4.731 & $10,59 \%$ \\
\hline & 3 & 1.095 & $2,45 \%$ \\
\hline & 4 & 3.818 & $8,55 \%$ \\
\hline & 5 & 45 & $0,10 \%$ \\
\hline \multirow{3}{*}{$\begin{array}{c}\text { Đối tượng } \\
\text { đến KCB } \\
\text { theo nớ } \\
\text { đăng ký } \\
\text { KCB BĐ }\end{array}$} & ĐK KCB BĐ & 10.538 & $23,59 \%$ \\
\hline & Đa tuyến nội tỉnh & 22.198 & $49,68 \%$ \\
\hline & $\begin{array}{l}\text { Đa tuyến } \\
\text { ngoại tỉnh }\end{array}$ & 11.942 & $26,73 \%$ \\
\hline \multirow{4}{*}{$\begin{array}{l}\text { Đối tượng } \\
\text { đến KCB }\end{array}$} & Đúng tuyến & 26.912 & $60,24 \%$ \\
\hline & Cấp cứu & 3.264 & $7,30 \%$ \\
\hline & Trái tuyến & 12.913 & $28,90 \%$ \\
\hline & Thông tuyễn & 1.589 & $3,56 \%$ \\
\hline \multirow{3}{*}{$\begin{array}{l}\text { Tuyênn } \\
\text { CMKT }\end{array}$} & TW & 17.81 & $39,86 \%$ \\
\hline & Tỉnh & 16.136 & $36,12 \%$ \\
\hline & Huyện & 10.732 & $24,02 \%$ \\
\hline \multirow{5}{*}{ Hạng BV } & $\mathrm{DB}$ & 2.017 & $4,51 \%$ \\
\hline & 1 & 24.261 & $54,31 \%$ \\
\hline & 2 & 16.884 & $37,79 \%$ \\
\hline & 3 & 1076 & $2,41 \%$ \\
\hline & Chưa phân hạng & 440 & $0,98 \%$ \\
\hline \multirow{3}{*}{$\begin{array}{c}\text { Loại hình } \\
\text { BV }\end{array}$} & Công lập & 44.238 & $99,02 \%$ \\
\hline & Ngoài công lập & 440 & $0,98 \%$ \\
\hline & Tống & 44,678 & \\
\hline
\end{tabular}

Xét về đăcc điểm nhân khẩu học: Tỷ trọng lượt điều trị nội trú ở nam cao gấp 1,45 lần ở nữ giới. Tỷ trọng số lượt điều trị nội trú của nhóm dưới 45 tuổi chiếm tỷ lệ cao nhất. Điều này phù hợp với tỷ trọng lượt điều trị nội trú của đối tượng tham gia BHYT chủ yếu là Nhóm 3 (Nhóm trẻ em dưới 6 tuổi-Nhóm do ngân sách nhà nước đóng,) đồng thời phù hợp với tỷ trọng lượt điều trị nội trú của người có mã quyền lợi 1 là chủ yếu.

Xét về phía người bệnh tham gia BHYT: Tỷ trọng lượt nội trú của đa tuyến nội tỉnh chiếm tỷ lệ cao nhất (49,58\%), người đi KCB tại nơi đăng ký KCB ban đầu và bệnh nhân tỉnh khác chiếm tỷ lệ tương đương nhau. Nằm điều trị nội trú chủ yếu là các bệnh nhân đi $\mathrm{KCB}$ đúng tuyến (chiếm 60,24\%).

Xét về phía bệnh viện: Số lượt điều trị nội trú tập trung chủ yểu ở các bệnh viện tuyến Trung ướng; các bệnh viện hạng 1.

\section{Bảng 2. Ngày điều trị nội trú trung bình}

\begin{tabular}{|c|c|c|c|}
\hline \multicolumn{2}{|c|}{ Các đặc điểm } & \multirow{2}{*}{$\begin{array}{c}\begin{array}{c}\text { Tân } \\
\text { suất }\end{array} \\
26.614 \\
\end{array}$} & \multirow{2}{*}{\begin{tabular}{|c|} 
Số \\
ngày \\
diêu tri \\
trung \\
bình \\
8,62 \\
\end{tabular}} \\
\hline \multirow{2}{*}{ Giới } & Nam & & \\
\hline & Nữ & 18.064 & 8,54 \\
\hline \multirow{3}{*}{ Nhóm tuổi } & $<45$ & 37.130 & 8,11 \\
\hline & $45-60$ & 1.814 & 11,06 \\
\hline & $>60$ & 5.734 & 10,91 \\
\hline \multirow{6}{*}{$\begin{array}{c}\text { Nhóm đối } \\
\text { tượng tham } \\
\text { gia BHYT }\end{array}$} & Nhóm 1 & 632 & 9,65 \\
\hline & Nhóm 2 & 2.553 & 11,61 \\
\hline & Nhóm 3 & 38.454 & 8,27 \\
\hline & Nhóm 4 & 1.248 & 8,66 \\
\hline & Nhóm 5 & 1.788 & 10,58 \\
\hline & Nhóm 6 & 3 & 8,00 \\
\hline \multirow{5}{*}{ Mã quyên lợi } & 1 & 34.989 & 8,05 \\
\hline & 2 & 4.731 & 10,91 \\
\hline & 3 & 1.095 & 11,05 \\
\hline & 4 & 3.818 & 9,85 \\
\hline & 5 & 45 & 12,22 \\
\hline \multirow{3}{*}{$\begin{array}{l}\text { Đối tượng đến } \\
\text { KCB theo nơi } \\
\text { đăng ký KCB } \\
\text { BĐ }\end{array}$} & ĐK KCB BĐ & 10.538 & 8,19 \\
\hline & Đa tuyến nội tỉnh & 22.198 & 8,20 \\
\hline & $\begin{array}{l}\text { Đa tuyến } \\
\text { ngoại tỉnh }\end{array}$ & 11.942 & 9,66 \\
\hline \multirow{4}{*}{$\begin{array}{l}\text { Đối tượng đến } \\
\text { KCB }\end{array}$} & Đúng tuyến & 26.912 & 9,11 \\
\hline & Cấp cứu & 3.264 & 8,74 \\
\hline & Trái tuyến & 12.913 & 7,57 \\
\hline & Thông tuyến & 1.589 & 7,69 \\
\hline \multirow{3}{*}{ Tuyến CMKT } & TW & 17.810 & 9,41 \\
\hline & Tỉnh & 16.136 & 8,59 \\
\hline & Huyện & 10.732 & 7,21 \\
\hline \multirow{5}{*}{ Hạng BV } & $\mathrm{DB}$ & 2.017 & 10,44 \\
\hline & 1 & 24.261 & 9,14 \\
\hline & 2 & 16.884 & 7,72 \\
\hline & 3 & 1.076 & 6,80 \\
\hline & Chưa phân hạng & 440 & 7,08 \\
\hline \multirow{3}{*}{\begin{tabular}{|r} 
Loại hình BV \\
$\mathbf{T}$
\end{tabular}} & Công lập & 44.238 & 8,60 \\
\hline & Ngoài công lập & 440 & 7,08 \\
\hline & Tống & 44.678 & 8,59 \\
\hline
\end{tabular}

Ngày điều trị trung bình ở nhóm tuối dưới 45 ở bệnh Viêm phổi là thấp nhất, và nhóm tuổi từ 
45 -60 tuổi có ngày điều trị trung bình cao nhất. bình cao nhất. Ngày điều trị trung bình tại các Nhóm đối tượng hưu trí, trợ cấp; Nhóm đối bệnh viện tuyến Trung ương, hạng đặc biệt là tượng đa tuyến ngoại tỉnh có ngày điêu trị trung cao nhất.

Chi phí điêu trị nội trú Viêm phổi của người có thẻ BHYT trên địa bàn Hà Nội năm 2018

Bảng 3. Cơ câú chi phí điều trị của bệnh Viêm phổi năm 2018

\begin{tabular}{|c|c|c|c|c|}
\hline \multirow{2}{*}{ Loại chi phí } & \multicolumn{4}{|c|}{ Viêm phổi } \\
\cline { 2 - 5 } & Trung bình & Độ lệch chuẩn & Tỷ lệ & Trung vị \\
\hline Xét nghiệm & 952.100 & 2.933 .106 & $16,6 \%$ & 361.263 \\
\hline CĐHA, TDCN & 202.438 & 461.391 & $3,5 \%$ & 69.000 \\
\hline Thuốc & 1.822 .730 & 6.804 .524 & $31,7 \%$ & 639.729 \\
\hline PTTT & 581.367 & 3.151 .994 & $10,1 \%$ & 211.200 \\
\hline VTYT & 271.729 & 3.358 .016 & $4,7 \%$ & 68.880 \\
\hline Giường bệnh & 1.862 .977 & 2.381 .994 & $32,4 \%$ & 1.428 .000 \\
\hline Máu & 56.101 & 964.093 & $1,0 \%$ & - \\
\hline Vận chuyến & 1.021 & 17.905 & $0,0 \%$ & - \\
\hline Tống & $\mathbf{5 . 7 5 0 . 4 6 3}$ & $\mathbf{1 6 . 1 0 4 . 8 8 9}$ & & $\mathbf{2 . 9 3 1 . 1 9 0}$ \\
\hline
\end{tabular}

Chi phí giường bệnh chiếm tỷ trọng cao nhất (32,4\%), tiếp đến là chi phí thuốc (31,7\%), chi phí xét nghiệm, chẩn đoán hình ảnh, thằm dò chức năng $(20,1 \%)$.

Bảng 4. Chi phí điều trị nội trú trung bình theo các đặc điểm của đôi tượng nghiên cứu

\begin{tabular}{|c|c|c|}
\hline Đặc điếm & Chi phí trung bình & Trung vị (Nhỏ nhất-Lớn nhất) \\
\hline Nam & 5,97 & $2,95(0,06-1.353,73)$ \\
\hline Nữ & 5,43 & $2,89(0,16-452,79)$ \\
\hline Nhóm tuổi: & 4,58 & \\
\hline $45-60$ & 11,84 & \\
\hline$>60$ & 11,41 & \\
\hline \multicolumn{3}{|c|}{ Đối tượng đến KCB theo nơi đăng ký KCB BĐ } \\
\hline ĐK KCB BĐ & 4,01 & $2,5(0,13-192,82)$ \\
\hline Đa tuyến nội tỉnh & 4,91 & $2,75(0,06-550,02)$ \\
\hline Đa tuyến ngoại tỉnh & 8,85 & $4,02(0,16-1.353,73)$ \\
\hline Đối tượng đến KCB: Đúng tuyến & 6,82 & $2,93(0,06-1.353,73)$ \\
\hline Cấp cứu & 5,75 & $2,88(0,20-297,77)$ \\
\hline Trái tuyến & 3,98 & $3,11(0,16-308,77)$ \\
\hline Thông tuyễn & 2,05 & $1,82(0,21-26,87)$ \\
\hline \multicolumn{3}{|c|}{ Đối tượng đến KCB theo nơi đăng ký KCB BĐ } \\
\hline ĐK KCB BĐ & 4,01 & $2,5(0,13-192,82)$ \\
\hline Đa tuyến nội tỉnh & 4,91 & $2,75(0,06-550,02)$ \\
\hline Đa tuyến ngoại tỉnh & 8,85 & $4,02(0,16-1.353,73)$ \\
\hline Đối tượng đến KCB: Đúng tuyến & 6,82 & $2,93(0,06-1.353,73)$ \\
\hline Cấp cứu & 5,75 & $2,88(0,20-297,77)$ \\
\hline Trái tuyến & 3,98 & $3,11(0,16-308,77)$ \\
\hline Thông tuyến & 2,05 & $1,82(0,21-26,87)$ \\
\hline Tuyến CMKT: & 8,59 & $4,09(0,16-1.353,73)$ \\
\hline Tỉnh & 4,95 & $2,91(0,13-297,77)$ \\
\hline Huyện & 2,24 & $2,08(0,06-28,52)$ \\
\hline Hạng BV: & 16,96 & $6,10(0,16-1.353,73)$ \\
\hline 1 & 7,09 & $3,82(0,13-1.034,82)$ \\
\hline 2 & 2,72 & $2,21(0,06-118,92)$ \\
\hline 3 & 1,83 & $1,72(0,18-10,32)$ \\
\hline $4, \mathrm{CH}$ & 6,28 & $2,26(0,18-195,60)$ \\
\hline Loại hình bệnh viện: Công lập & 5,75 & $2,94(0,06-1.353,73)$ \\
\hline Ngoài công lập & 6,28 & $2,26(0,18-195,60)$ \\
\hline
\end{tabular}




\section{BÀN LUÂN}

Quan điểm về chi phí trong nghiên cứu. Chính sách viện phí tại Việt Nam giai đoạn từ 2015 cho đến nay thiviệc thu viện phí được áp dụng bao gồm các chi phí sau: i) Chi phí trực tiếp: Chi phí về thuốc, dịch truyền, hóa chất, vật tư tiêu hao, vật tư thay thế; Chi phí về điện, nước, nhiên liệu, xử lý chất thải, vệ sinh môi trường; Chi phí duy tu, bảo dưỡng thiết bị, mua thay thế công cụ, dụng cụ. ii) Chi phí phụ cấp thường trực, phụ cấp phẫu thuật, thủ thuật (phụ cấp đặc thù). iii) Chi phí tiên lương theo lương ngạch bậc, chức vụ, các khoản phụ cấp, các khoản đóng góp theo chế độ do Nhà nước quy định đối với đơn vị sự nghiệp công lập (2-4).

Như vậy, trong thời gian tiến hành nghiên cứu (năm 2018) thì giá viện phí chưa bao gồm chi phí khấu hao tài sản cố định, chi phí quản lý (Chi phí của bộ phận gián tiếp, các chi phí hợp pháp khác để vận hành, bảo đảm hoạt động bình thường của bệnh viện, Chi phí đào tạo, nghiên cứu khoa học để ứng dụng các kỹ thuật mói) $(5,6)$.

Ngoài ra, do hạn chế trong việc thu thập số liệu, vì vậy trong luận văn này chỉ tính toán chi phí cho điêu trị trong phạm vi thanh toán của quỹ BHYT (Quan điểm chi phí của người quản lý quỹ $B H Y T$ và Quan điểm chi phí của người sử dụng dịch vụ y tế).

Chi phí trung bình điêu trị nội trú Viêm phổi tại Hà Nội năm 2018. Xét theo giới tính thì chi phí điều tri nôi trú bênh Viêm phổi ở nam giới cao hơn nữ giới ( 5,9 triệu đồng/lượt so với 5,4 triệu đồng/lượt). Nghiên cứu của Trương Công Trứ cũng cho kết quả chi phí điều trị trực tiếp ở nam giới cao hơn nữ giới (7).

Xét theo nhóm tuổi thì bệnh Viêm phổi có chi phí điều trị ở nhóm từ $45-60$ tuổi là cao nhất ( 11,8 triệu đồng/lượt), thấp nhất là nhóm dưới 45 tuổi ( 4,54 triệu đồng/lượt).

Xét theo đối tượng tham gia BHYT ở bệnh Viêm phổi thì nhóm đối tượng hưu trí, hưởng trợ cấp có chi phí điều trị nọi trú cao nhất ( 13,8 triệu đồng/lượt), tiếp đến là nhóm đối tượng người lao động ( 13,2 triệu đồng/lượt). Kết quá nghiên cứu của Dương Tuấn Đức cũng cho kết quả tương tự đó là nhóm hưu trí, mất sức có chi phí bình quân một đợt điều trị là cao nhất (8).

Xét theo đối tượng đến KCB thì đối tượng bệnh nhân ngoại tỉnh ( 8,8 triệu đồng/lượt) là nhóm đối tượng có chi phí điều trị nội trú cao nhất, đối tượng đăng ký KCB ban đâuu ( 2,5 triệu đồng/lượt) và đối tượng đi $K C B$ thông tuyến ( 2 triệu đồng/lượt) là nhóm đối tượng có chi phí trung bình điều trị nội trú thấp nhất. Nguyên nhân một phần là do các bệnh viện tuyến trên ở Hà Nội không chỉ làm nhiệm vụ tiếp nhận bệnh nhân năng tữ các tuyến dưới của thành phố mà còn là tuyến cuối của cả nước vì vậy còn tiếp nhận các trường hợp bệnh nhân nặng từ các tỉnh, thành phố khác.

Xét theo tuyến chuyên môn kỹ thuật thì chi phí điều trị nội trú của tuyến Trung ương cao nhất, kết quả này tương đồng với các kết quả của những nghiên cứu trước đây.

Xét theo hạng bệnh viện thì chi phí điều trị nội trú của hạng đặc biệt là cao nhất, nguyên nhân chủ yếu là do danh mục thuốc được sử dụng, mức giá dịch vụ y tế được quy định theo từng phân hạng bệnh viện.

Xét theo loại hình bệnh viện thì chi phí của các bệnh viện ngoài công lập cao hơn chi phí của các bềnh viện công lập. Tuy nhiên do số lượt điều trị ở các bệnh viện ngoài công lập chênh lệch lớn so với công lập.

Han chế của nghiên cứu: Nghiên cứu chỉ thực hiện trên chi phí KCB BHYT của người bệnh BHYT (chưa được tính toán đầy đủ chi phí vào giá dịch vụ y tế) tại các cơ sở KCB, không đề cập đến các chi phí khác từ phía người bệnh, chi phí cơ hội và một số yếu tố liên quan khác.

\section{KẾT LUÂ̂N VÀ KHUYẾN NGH!}

Chi phí điều trị nội trú trung bình của bệnh Viêm phổi là 5.750 .463 đồng/lượt, trong đó cơ cấu chi phí trung bình một đợt điều trị bênh Viêm phổi thì chi phí giường bênh chiếm tỳ trọng lớn nhất $(32,4 \%)$, tiếp đến là tiền thuốc $(31,7 \%)$, XN và $\mathrm{CĐHA}(20,1 \%)$;

\section{TÀI LIÊU THAM KHẢO}

1. Bảo Hiểm Xã Hội Việt Nam. Báo cáo kết quả công tác năm 2020 và phương hướng nhiệm vụ năm 2021. 2021.

2. Bộ Y Tế. Quy định thống nhất giá dịch vụ khám bệnhn, chữa bềnh bảo hiểm y tế giữa các bệnh viện cưng hạng trển toàn quốc và hướng dẫn áp dung giá, thành toán chi phí khám bênh, chữa bềnh trong một số trường hợp. 2018;Thông tư số 39/2018/TT-BYT.

3. Bố Y Tế. Quy định thống nhất giá dịch vụ khám bệnh, chữa bênh bảo hiểm y tế giữa các bệnh viện cùng hang trến toàn quốc và hướng dẩn áp dung giá, thanh toán chi phí khám bệnh, chữa bệnh trong một số trường hợp. 2018; Thông tư số 15/2018/TT-BYT.

4. Bố Y Tế - Bộ Tài Chính. Quy định thống nhất giá dich vu khám bênh, chữa bênh bảo hiểm y tế giứa các bệnh viện cùng hang trên toàn quốc. 2015; Thông tư liên tịch sổ 37/2015/TTLT-BYT-BTC.

5. Chính Phủ. Quy định cơ chế tự chủ của đớn vị sự nghiệp công lập. 2015;Nghị định số 16/2015/ND-CP. 
6. Chính Phủ. Về cơ chế hoạt động, cơ chế tài chính đối với các đơn vị sự nghiệp y tế công lập và giá dịch vụ KCB cưa các cơ sở KCB công lập. 2012;Nghị định số 85/2012/NĐ-CP

7. Trương Công Thứ. Chi phí điều tri nội trú bệnh phổi tắc nghển mãn tính, viêm phổi và ung thư phổi tại Bệnh viện 74 Trung ương, năm 2014. Luận văn Thac sĩ quản lý bênh viện. 2014.

8. Dương Tuấn Đức. Nghiên cứu cơ cấu bênh tâtt và chi phí của người bệnh bảo hiểm y tế điều trị nội trú tại Hà Nội năm 2004. Luận văn thạc sỹ y tế công cộng. 2004.

\title{
ĐÁNH GIÁ MỨC Độ HÀI LÒNG CỦA NGƯỜI BỆNH CHUẨN BI NộI SOI ĐẠI TRÀNG ĐƯợC HƯỚNG DẪN BẰNG ỨNG DỤNG TRÊN ĐIẾN THOÄI THÔNG MINH
}

\author{
Phan Thị Hồng Tuyên ${ }^{1}$, Đào Việt Hằng 1,2,3, \\ Lâm Ngọc Hoa ${ }^{3}$, Đào Thị Loan ${ }^{1}$, Danh Thị Phượng ${ }^{1}$, \\ Ngọ Thị Phương Dung1, Đào Văn Long 1,2,3
}

\section{TÓM TẮT}

Nghiên cứu đánh giá mức độ hài lòng và các yếu tố liên quan đến mức độ hài lòng của người bệnh với hướng dẫn CBĐT trên Đ̇TTM. Thử nghiệm lâm sàng được tiến hành trên nhóm người bênh 18-75 tuổi có sử dụng điện thoại thông minh (ĐiTM), có chỉ định nôi soi đai tràng (NSĐT) cùng ngày khám tai bếnh viện Đại học Y Hà Nội tữ 9/2020 đến 5/2021. Nhóm chứng được hướng dẫn chuẩn bi đại tràng (CBĐT) như thường quy $(n=281)$ và nhóm can thiệp được hướng dẫn như thường quy kèm sự hồ trợ của ứng dựng trong hố trợ CBĐT trên ĐTTM $(n=233)$. Đặc điểm về giới, khu vực sinh sống, trình độ học vấn, lý đo đi khám và triệu chứng lâm sàng không có sự khác biệt có ý nghĩa thống kê giữa hai nhóm. Tî lệ cao người bệnh hài lòng với quá trình hướng dẫn $\mathrm{CBĐT}$ với hố trợ của ứng dụng trên ĐTTM (96,9\%). Điểm trung bình mức đô hài lòng với ứng dụng là $4,6 \pm 0,4$, tỉ lể hài lòng đạt $98,7 \%$. Các yếu tố về đặc điểm của người bệnh không có mối liên quan đến điểm mức độ hài lòng của người bệnh với ứng dụng hỗ trợ CBĐT trên ĐTTM.

Từ khóa: chuẩn bị đại tràng, mức độ hài lòng, ứng dụng.

\section{SUMMARY}

EVALUATE PATIENT'S SATISFACTION ON A MOBILE APPPLICATION IN COLONOSCOPY BOWEL PREPARATION

Our study aimed to evaluate patient's satisfaction and its associated factors on a mobile applicationin colonoscopy bowel preparation. A randomized controlled study was conducted among patients aged 18-75, using smartphone and indicated colonoscopy

${ }^{1}$ Bênh viên Đai hoc Y Hà Nôi

${ }^{2}$ Trường Đại học Y Hà Nội

32Viện nghiên cứu và đào tạo Tiêu hoá, Gan mật

Chịu trách nhiệm chính: Phan Thị Hồng Tuyên

Email: hatuyen110879@gmail.com

Ngày nhận bài: 9.7.2021

Ngày phản biên khoa họ: 3.9.2021

Ngày duyệt bài: 13.9.2021 within the same day at Hanoi Medical University Hospital between $9 / 2020$ and 5/2021. Patients in intervention group were used a mobile app besides the routine bowel preparation guidance $(n=233)$, patients in controlled group were only approached to the routine guidance $(n=281)$. The characteristics of gender, living area, educational level, chief complaints, and clinical symptoms were not significantly different between 2 groups. High proportion of patients was satisfied with bowel preparation guidance on mobile app $(96.9 \%)$. The mean of satisfaction score was $4.6 \pm 0.4$, the proportion of satisfaction was $98.7 \%$. No factor was found to be associated with patient's satisfaction on mobile application using on bowel preparation.

Keyword: colonscopy bowel preparation, satisfaction, smartphone application.

\section{I. ĐẶT VẤN ĐỀ}

Nội soi đại tràng (NSĐT) là một thăm dò hình ảnh quan trọng trong sàng lọc, chẩn đoán và điều trị các bệnh lý đường tiêu hóa dưới. Để có đô chính xác phù hợp và đảm bảo an toàn của thủ thuật nội soi, người bệnh cần được tiến hành chuẩn bị đại tràng (CBĐT). Quá trình uống thuốc chuẩn bị đại tràng cho đên khi đạt chất lượng làm sach tối ưu cho thủ thuật nội soi thường kéo dài, đòi hỏi người bệnh thực hiện nhiều bước khác nhau, uống đủ nước kểt hợp với việc đi lại, xoa bụng để tăng thời gian lưu thông ruột. Một số người bệnh còn có thể gặp các triêu chứng không mong muốn trong quá trình uống thuốc như buồn nôn, nôn, mệt mỏi, đau đầu, chóng mặt, dị ứng... dẫn đến kéo dài thời gian CBĐT, có thể cần trĩ hoãn thủ thuật nội soi, hay nhập viện theo dõi. Do đó, CBĐT là một quá trình phức tạp, không thoải mái và có thể tạo cảm giác ngại và lo lắngvới nhiều người bệnh[3], [4]. Viêc hướng dẫn CBĐT để người bênh an tâm, dễ hiểu, dễ nhớ và tuân thủ với phác đồ vì vậy là bước rất quan trọng. Hiện nay, tại các cơ sở y tế, 